\title{
Essential Attribute of Educational Technology in Enhancing the Productivity of Education
}

\author{
Zhenfang Liu \\ Normal College, Jinhua College of Profession and Technology, Jinhua, 321007, China
}

email: liuzf3075@163.com

Keywords: educational technology; attribute; educational productivity; education reform;application

\begin{abstract}
As an organic part of education informatization, the educational technology plays a pivotal role in the critical period when the nation implements the Outline of the National Medium-and Long-Term Program for Education Reform and Development plan (2010-2020).To clarify the essential attribute of educational technology, and define the functional role of educational technology has a special meaning for the disciplines construction of educational technology and its career development, and would have a far-reaching meaning for the education reform and development. At the same time, it is also the necessary and sufficient condition for the correct positioning of educational technology and its healthy sustainable development.
\end{abstract}

\section{The Connotation of Educational productivity}

Education is a Social activity that Purposefully to impart knowledge, develop skills (ability to learn), and good moral character to the people. It generated to adapt to the need to teach the skills, experience and social life of productive labor, and developed along with social progress.

With the profound impact of technological revolution of Contemporary Sciences to human society's mode of production and way of life and way of thinking, the situation is Increasingly prominent that Socialization of science and technology, and the science technology of the community. It has been a consensus of people that "Science and technology are the primary productive forces". Science and technology are productive forces, education is also productive force. when understanding of the scope of productivity, People usually takes labor materials, the object of labor and laborers as the three substantive elements constitute productivity, but takes the science and technology understanding for the non-substantive elements or "intelligence factor" in productive forces. There are three avenues that must go through if we want realize the transition from non-substantive elements to the substantive elements. The First avenue, making the scientific knowledge materialized to the labor materials, changing the nature and level of production data. The second avenue, materializing scientific knowledge to the subject of labor, changing the subject of labor conditions and scope. The third avenue, arming workers with scientific knowledge, improving and strengthening the intellectual and production skills of workers.

The process of materializing Scientific knowledge or objecting to the subject of labor, the process labor materials and laborers, is exactly the process that science changes into the direct productivity. I think the main avenue of the above three is "arming workers with scientific knowledge". Only in this way, we can make scientific knowledge materialized to the subject of labor and labor materials through the practice of workers. To realize the materialization,, it is absolutely impossible to leave the education. The so-called educational productivity is the labor skills of educators to implement the education and teaching activities.

In fact, productivity is a complex dynamic system of multi-level. In addition to the previously mentioned three substantive elements and the intellectual element of science and technology, the productivity also includes elements of education and management. We can take the substantive elements of the productivity as the "hardware", take the science and technology, education and management as "software" elements. The workers are the primary productivity and the dominant factors in the "Hardware" elements; Science and technology and education has an equally important role in the "software" elements. Education as the carrier of science and technology, it provide the 
necessary conditions for the development of science and technology. In other words, Technology development must rely on education, and take it as the basic tools and instruments. At the same time, through the education teaching and create scientific and technological knowledge, it Makes science and technology knowledge and laborer to combinate, and to penetrate to the other elements of productivity, and it changes science and technology into direct, realistic, specific productivity.

So we can see, the constitute elements of Education and productivity are all people engaged in the production of education and its relationship that happened. These elements include education departments, parents, schools, teachers and students, and also include teaching facilities, educational technology, education and management. Among educational productivity factors, Educational technology is the key. Only through technology, re-designing the educational process and changing the structure of education, can educational productivity be improved [1].

\section{The Essential Attribute of Education}

Education is a kind of social activities that implemented according to theoretical guidance, system planning and design.This is the basic understanding of human being for essential question of education [2].

Education is a kind of social activities of both theory and practice .The system of education include Education theory category subject of teaching theory, learning theory, etc; education practice category subject of method of teaching, etc. Being a kind of social activity , education must be combination of theroy and practice, also realize the organic combination of education theory and education practice. While The reality is the disruption of education theory and education practice. The origin of the gap between saying and doing lies in that there lack of a connectional bridge between education theory and education practice. Although education technology are the bridge, due to the delay understanding of educational circles; the drift and generalization of Education technology's own development in recent years, thus delay the process of human's recognization .

As well as other education branch discipline, education technology is also used to improve and enhance the teaching effect. As a cross subject, Education technology is combined with a variety of theories and ideas, such as Education theory, learning theory, communication, system theory, etc, to improve the development of human being to chase for the goal. In the meantime, there has a lot of unique place on Education technology in solving education problems in teaching methods, means and technology compared with other disciplines. Improving productivity of education is he most fundamental attributes of Education technology.

Education technology is a bridge connecting human's reproduction and revealing the law of development of science .Education technology has a promoting effect on human reproduction and related subjects, places of human reproduction is the application of education technology. Pedagogy, study theory, behavioral science, brain science reveals the law of the development from different angles. Education technology apply the law to practice and seek appropriate techniques in order to improve the efficiency and effectiveness of human reproduction [3]. Education technology is a bridge that crosses from the education theory and education practice. Or, in central China normal university, zhu egui's view: education technology is connected to the human reproduction and reveal the law of development of science. Education technology is a application field to provide theory construction and practice of education reform and technical support, and improve the education of the productive forces. With this in mind, we should know what to do in the new era of education technology and understand what should the education technology to do for education reform and development .

\section{The fundamental way to improve educational productivity}

The domestic scholars believe that the main factors affecting the productivity of education is " the quality of school education ", which refers to improve the quality of teaching various disciplines in schools and the comprehensive quality of students. The fundamental way to significantly 
improve the educational productivity ( and the only way ) is to implement some major structural changes on the education system By the support of technology [4].

Educational technology includes not only tangible" materialized technology" (It contains hardware technology and software technology of Technology ), but also intangible“intelligent technology”. Meanwhile, it includes not only modern technology, but also the traditional technology. If you want to improve the output and productivity of education, then you must use technology to change the basic structure of education and redesign the process of education. Professor Kekang He believes that the exact meaning of "the structural change about school education system " is to realize the fundamental change of the classroom teaching structure [5]. That is, to build a kind of information teaching environment by effectively fusion information technology into each subject's teaching process. And through this way, they can realize a new mode of teaching and learning which take " Autonomy, inquiry, cooperation" as its characteristics. Meanwhile this new mode can not only give full play to the leading role of the teacher but also highlight the dominant position of students. This approach has two results. One is that the student's initiative, enthusiasm, creativity can put into full play. And the other is that the traditional teaching structure has changed radically, which refers to the teaching structure changed from "teacher-centered" to "teacher-led-learner-centered combination" teaching structure.

we can say that Educational technology must serve as the motive force theory of education development. Educational technology has the nature of technology. This make Educational technology has advanced educational philosophy, possesses the integrated and applicable ideas and means to modern media technology, and have the practical operation and application. So, we can conclude that Educational technology is the link and bridge between the Teaching theory and education practice. It is the transmission belt and booster from theory to activity ,from theory to practice in educational practice. Educational technology has integrated a variety of ideas and theories. Its theoretical foundation includes the theory of education, learning theory, communication theory, system theory and so on. Interdisciplinary research makes Educational technology paid more attention to he effective application of technology, also paid more attention to the equal status of teachers and students and paid more attention to the design and support of learning activities and learning processes. For the present, the educational application of educational technology is mainly reflected in the aspect that be based on modern information technology, do teaching design, and optimize teaching process. The center of educational application is improving the educational productivity for educators. This productivity's specific expression is the ability of teaching design, course development and educational project management which is based on modern education media [6].

Secondly, from the view of technology, Educational technology has the basic characteristics of digital, networked, intelligent and multimedia. Multimedia technology, artificial intelligence technology and virtual reality technology can bring new ideas and new methods for teaching and experiment. All of these will have a more profound impact on teaching methods, learning styles and teaching mode. Audio-visual database, online resources, online courses, online teacher training program, professional teaching knowledge base provides a very convenient conditions for learners. There comes out model of instruction , which suits for Individual learning, group learning and problem-based learning, e-Learning, blended learning and other learning methods. The classroom teaching's limit of time and space has also being broken by using technology.

\section{Thinking on education technology development}

The professor of East China normal university hold the view that, as an important part of educational development ,the development of education technology plays an important role in education ,especially the development of basic education. First of all is that it lay a viable and new development foundation for the implementation of quality education, and then is to promote education modernization with the development of education technology [7].

In terms of teacher education reform, it should be said unshakable responsibility and obligation. Both long term training or short-term training, education technology should be to enhance 
productivity and try our best to education. Virtual environment in the development of teachers' subject teaching experimental research and application achievements, is an urgent need to set up virtual reality education teaching experiment system, and make full use of immersion virtual reality technology, interactive and ideas, improving the quality and effect of teaching and learning in many aspects. We need a system to organize the whole plan of different information technology and classroom teaching, teacher training, teacher's professional cooperative overall scheme, especially in teacher education technology environment and the technology platform of design idea, etc, for provide full technical support for teachers' professional development.

Today's education technology application, more sense is a kind of idea, mode, the behavior of the application guide. Not to put the education technology work center of gravity from theory to practice, but to pay attention to media technology from the technology, to pay attention to teaching design technology; From the research and application of drift generalization to directivity more specific research and application of more mature more specific. Education media, not only refers to the current application of information technology in education in the application of computer and network, but also including existing a variety of audio-visual media in the past, will also include new information technology and new media.

Melting, regression and development of education technology, is fully in accordance with the education reform and development needs. In the national medium and long-term education reform and development compendium, the important point is to accelerate the development of education informatization, the development of education informatization requires education technology effective theoretical guidance and technical support, more need to conform to the education of modern education idea productivity improvement. There is no doubt that all of this provides a new great quantity loose harmonious practice field for the development of education technology.In the current era of information, as education teaching process optimization and teaching process, in order to improve the triple effect (effect, efficiency and effectiveness) of the main technologies, of course, is representing the most advanced productivity of information technology.

\section{Conclusion}

Education technology education as the secondary discipline, its education attribute is not changed. Education technology is neither a part of the education theory, nor a part of the education practice, education technology is the bridge that crosses from the education theory and education practice subject, its nature is to promote education of the productive forces. Education technology has promoting effect on human reproduction and related subjects, places of human reproduction is the application of education technology, improve education productive force is the historical responsibility of education technology. Education technology discipline construction must be based on information technology, starting from the teaching design, construction of teaching theory, learning theory and combined with the field of education teaching practice and discipline system. Only so, education technology can do what you should do, to highlight its irreplaceable in education, to reform and education modernization construction of sustainable development.

\section{References}

[1][4][5] Kekang He. About the 2010 U.S. national education technology plan of learning and thinking. e-Education Research, 2011, (4):8-23.

[2] Kaicheng Yang. The awkward of China's education technology.CET China Educational Technology, 2005, (12):11-14.

[3]Egui Zhu. Improve the performance of human reproduction technology-Our concept of education technology. CET China Educational Technology, 2005,(12):13-16.

[6][7]Gang Ding,Lu Wang.Under the pedagogy Angle of view of education technology subject development. e-Education Research, 2006, (8) 